\title{
Change in Gamma Prime Morphology and Dislocation Substructures of Single Crystal Nickel-Based Superalloy, CMSX-4, Pre-Crept at 1273K-400MPa with Simple Aging
}

\author{
Y. Kondo and N. Miura ${ }^{\mathrm{b}}$ \\ Department of Mechanical Systems Engineering, National Defense Academy, \\ Yokosuka Kanagawa, Japan
}

akondo@nda.ac.jp, ${ }^{b}$ nmiura@nda.ac.jp

Key words: Superalloy, Creep, g' precipitates, Dislocation substructure, aging

\begin{abstract}
The single crystal nickel-based superalloy, CMSX-4, creep interrupted at the creep strain of 0.01 at $1273 \mathrm{~K}-400 \mathrm{MPa}$ was aged at $1273 \mathrm{~K}$ without stress to make clear the $\gamma / \gamma^{\prime}$ rafting mechanism. And the changes in the $\gamma^{\prime}$ morphology and the dislocation substructures at the $\gamma / \gamma^{\prime}$ interface with simple aging time were studied and compared with the previous work at $1273 \mathrm{~K}-250 \mathrm{MPa}$. The cuboidal $\gamma^{\prime}$ precipitates were regularly arrayed when the creep test was interrupted, but changed to the rafted $\gamma / \gamma^{\prime}$ structures normal to the pre-creep stress axis with simple aging time. The aspect ratio of the $\gamma^{\prime}$ precipitates increased with increasing simple aging time up to $3.60 \times 10^{6} \mathrm{~s}$, attained to the maximum value and then decreased. The maximum value of the aspect ratio at $400 \mathrm{MPa}$ was lower than one at $250 \mathrm{MPa}$. A number of dislocations were tangled with each other at the $\gamma / \gamma^{\prime}$ interfaces of the creep interrupted specimen. These tangled dislocations were only rearranged by simple aging and the dislocation density at the $\gamma / \gamma^{\prime}$ interfaces was almost constant, independent of simple aging time. All dislocations of the creep interrupted specimen at the $\gamma / \gamma^{\prime}$ interfaces with six kinds of the $<110>$ Burgers vectors were detected equally. The proportion of the six kinds of the $<110>$ Burgers vectors didn't change with simple aging time.

Consequently, dislocations at the $\gamma / \gamma^{\prime}$ interfaces were considered as not the misfit ones, but the traces of mobile dislocations in the $\gamma$ channels and the formation of the rafted $\gamma / \gamma^{\prime}$ structures might be closely correlated with the rearrangement of tangled dislocations at the $\gamma / \gamma^{\prime}$ interfaces.
\end{abstract}

\section{Introduction}

The cuboidal $\gamma^{\prime}$ precipitates in the single crystal nickel-based superalloys with the stress axis of the [001] orientation turn its shape into the plate like ones perpendicular to the stress axis during high temperature creep deformation [1-6]. This drastic morphological change of the $\gamma$ ' precipitates is called as rafting. Though the various models on the rafting mechanism have been proposed [7-11], the rafting mechanism has not been fully understood, especially the role of dislocation on the rafting mechanism has not been fully discussed yet. It was well understood that rafting of the $\gamma / \gamma^{\prime}$ structures strongly depends on the creep testing conditions, such as time, temperature and stress [11]. These factors make it difficult to clarify the rafting mechanisms.

In our previous work, the single crystal nickel-based superalloy interrupted at the creep strain of 0.01 at $1273 \mathrm{~K}-250 \mathrm{MPa}$ was aged at $1273 \mathrm{~K}$ without stress and the changes in the $\gamma^{\prime}$ morphology and the dislocation substructures at the $\gamma / \gamma^{\prime}$ interfaces with simple aging time were studied. The nearly cuboidal $\gamma^{\prime}$ precipitates were regularly arrayed when the creep test was interrupted, but changed to the rafted $\gamma / \gamma^{\prime}$ structures with simple aging time. A number of dislocations which were tangled with each other at the $\gamma / \gamma^{\prime}$ interfaces of the creep interrupted specimen were only rearranged by simple aging and the dislocation density at the interfaces was almost constant, independent of simple aging time. All dislocations at the $\gamma / \gamma^{\prime}$ interfaces of the creep interrupted specimen and this aged ones have six kinds of the $<110>$ Burgers vectors equally [12], [13]. Based on these evidences, it was assumed that dislocations at the $\gamma / \gamma^{\prime}$ interfaces were considered as not the misfit ones, but the traces of mobile dislocations in the $\gamma$ channels and the formation of the rafted $\gamma / \gamma^{\prime}$ structures might be closely correlated with the rearrangement of tangled dislocations at the $\gamma / \gamma^{\prime}$ interfaces. 
The relationship between the formation of the rafted $\gamma / \gamma^{\prime}$ structures and the dislocation substructures should be discussed at the wide temperature and stress range, in order to be proved to be of great universality. However, The discussion on this relationship was undertaken at only one creep condition, at $1273 \mathrm{~K}-250 \mathrm{MPa}$.

In this study, the creep tests at $1273 \mathrm{~K}$ and $400 \mathrm{MPa}$ on the single crystal nickel-based superalloy, CMSX-4, with the stress axis of the [001] orientation are interrupted at the strain of 0.01 , and the changes in the $\gamma^{\prime}$ morphology and the dislocation substructures at the $\gamma / \gamma^{\prime}$ interfaces with simple aging time was investigated and compared with the previous work at $1273 \mathrm{~K}-250 \mathrm{MPa}$.

\section{Experimental Procedure}

A single crystal of the nickel-based superalloy of CMSX-4 (with a chemical composition in weight percent; $6.4 \mathrm{Cr}$, 9.3Co, 5.5Al, $0.9 \mathrm{Ti}, 0.6 \mathrm{Mo}, 6.2 \mathrm{Ta}, 6.2 \mathrm{~W}, 2.8 \mathrm{Re}, 0.1 \mathrm{Hf}$, balance $\mathrm{Ni}$ ), were prepared in the form of bars with $13 \mathrm{~mm}$ in diameter and $160 \mathrm{~mm}$ in length by a directional precision casting. From these bars, creep testing specimens with a gage portion of $8 \mathrm{~mm}$ in diameter and $40 \mathrm{~mm}$ length were machined. Three axes of these single crystals were determined by Laue X-ray back-reflection technique; the difference in angles between the stress axis and the pole of [001] in the standard stereographic triangle were within 5 degrees. The single crystal bars were normal solid solution treated and aged. The creep test was carried out at $1273 \mathrm{~K}$ and $400 \mathrm{MPa}$ under a constant load. Furthermore, the creep test was interrupted at the strain of 0.01 . Creep strain was measured automatically through the linear variable differential transformers (LVDTs) attached to the extensometer. The interrupted creep specimens were aged at $1273 \mathrm{~K}$ up to $1.08 \times 10^{7} \mathrm{~s}$ without the stress. Microstructure observations were carried out by a field emission scanning electron microscopy (FE-SEM) and a transmission electron microscopy (TEM) on the specimens sectioned parallel to the (100), (001) and (103). The specimens for the SEM observation were prepared metallographically and electroetched with a supersaturated oxialic acid aqueous solution. The aspect ratio of the $\gamma^{\prime}$ precipitates was measured by the digital image processor-analyzer and defined as the average length divided by the average width of the $\gamma^{\prime}$ precipitates. TEM foils were prepared by electropolishing using a twin jet polisher with the $10 \%$ perchloric acid-alcohol solution. The Burgers vector, $b$, of dislocations at the $\gamma / \gamma^{\prime}$ interfaces were identified by the $g \cdot b=0$ contrast invisibility criterion

\section{Results and Discussion}

\section{Microstructure of as-heat treated specimen}

The scanning electron micrograph of the as-heat treated CMSX-4 is shown in Fig.1. The cuboidal $\gamma^{\prime}$ precipitates in the $\gamma$ matrix are regularly arrayed. The average edge length of the cuboidal $\gamma^{\prime}$ precipitates is about $0.5 \mu \mathrm{m}$. The average width of the $\gamma$ channels is approximately $0.1 \mu \mathrm{m}$. The volume fraction of the $\gamma^{\prime}$ precipitates is estimated as $78 \%$. No eutectic $\gamma^{\prime}$ precipitates could be observed.

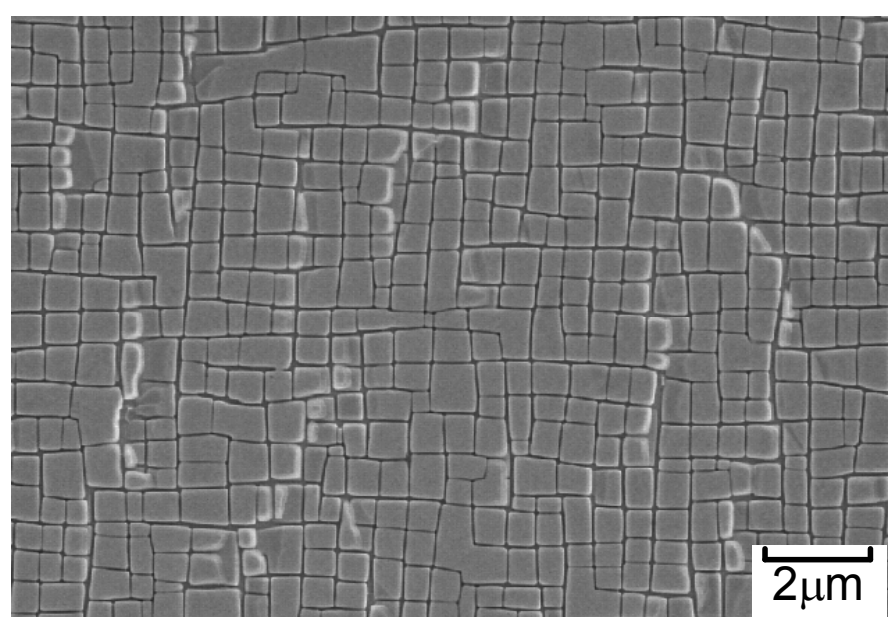

Fig. 1. Scanning electron micrograph of the single crystal nickel-based superalloy, CMSX-4.

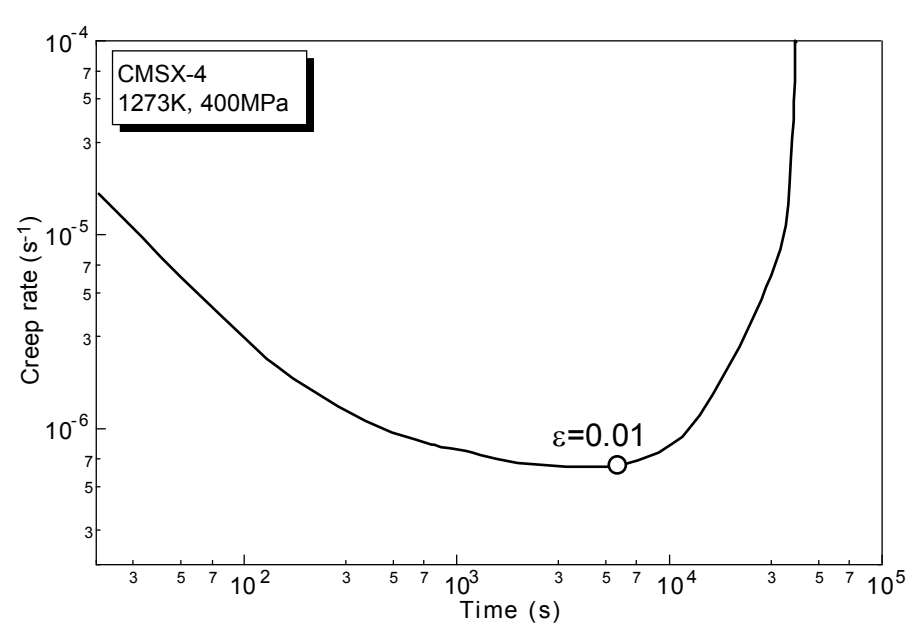

Fig. 2. The creep rate-time curve of CMSX-4 at $1273 \mathrm{~K}$ and $400 \mathrm{MPa}$. 


\section{Creep rate-time curve of CMSX-4 at $1273 \mathrm{~K}$ and $400 \mathrm{MPa}$}

The creep rate-time curve of CMSX- 4 at $1273 \mathrm{~K}$ and $400 \mathrm{MPa}$ consists of the transient creep stage and the accelerating creep stage, as shown in Fig.2. The open circle on the curve indicates the time when the creep test was interrupted, and this time is corresponded to the beginning of the accelerating creep stage.

\section{Morphological change of the $\gamma^{\prime}$ precipitates with simple aging}

The scanning electron micrographs of the interrupted creep specimen at the strain of 0.01 and the specimens aged for $1.08 \times 10^{6}$ and $3.60 \times 10^{6} \mathrm{~s}$ are shown in Fig.3. The cuboidal $\gamma^{\prime}$ precipitates in the interrupted creep specimen at the strain of 0.01, remains its shape (Fig.3-(a)). In the specimen aged for $1.08 \times 10^{6} \mathrm{~s}$, some of the cuboidal $\gamma^{\prime}$ precipitates connect each other in the direction perpendicular to the pre-creep stress axis (Fig.3-(b)). The fully rafted $\gamma / \gamma^{\prime}$ structures perpendicular to the pre-creep stress axis are observed in the specimen aged for 3.60x10 ${ }^{6}$ s (Fig.3-(c)). Consequently, the rafting of the $\gamma / \gamma^{\prime}$ structures can be confirmed in the interrupted creep specimen at the strain of 0.01 , only by subjecting the simple aging.

\section{Change in the aspect ratios of the $\gamma^{\prime}$ precipitates with increasing simple aging time}

To estimate the change from the cuboidal $\gamma^{\prime}$ precipitates to the rafted $\gamma / \gamma^{\prime}$ structures, the ratio of the length of the $\gamma^{\prime}$ precipitates to the width of the $\gamma^{\prime}$ precipitates, designated as the aspect ratio of the $\gamma^{\prime}$ precipitates is measured.

The aspect ratio of the $\gamma^{\prime}$ precipitates of the interrupted creep specimen at $400 \mathrm{MPa}$ is plotted as a function of simple aging time, as shown in Fig.4, compared with that of the interrupted creep specimen at $250 \mathrm{MPa}$. The aspect ratios of the $\gamma^{\prime}$ precipitates of the interrupted creep specimen at the strain of 0.01 are approximately 1 . However, both of the aspect ratios of the interrupted creep specimens at 400 and 250MPa increase with increasing simple aging time, and attained to the maximum value, at $3.60 \times 10^{6} \mathrm{~s}$, independent of stress. And then, the aspect ratio decreases with increasing aging time. The aspect ratios at $400 \mathrm{MPa}$ are lower than those at $250 \mathrm{MPa}$ at each aging time.

\section{Dislocation substructures at $\gamma / \gamma^{\prime}$ interface}

The TEM observations are examined by using the interrupted creep specimen and this simple aged specimens which were cut parallel to the (103) plane, to investigate the changes in the dislocation substructures at the $\gamma / \gamma^{\prime}$ interfaces parallel to the (001) plane with increasing aging time.

The transmission electron micrograph of the interrupted creep specimen is shown in Fig. 5,

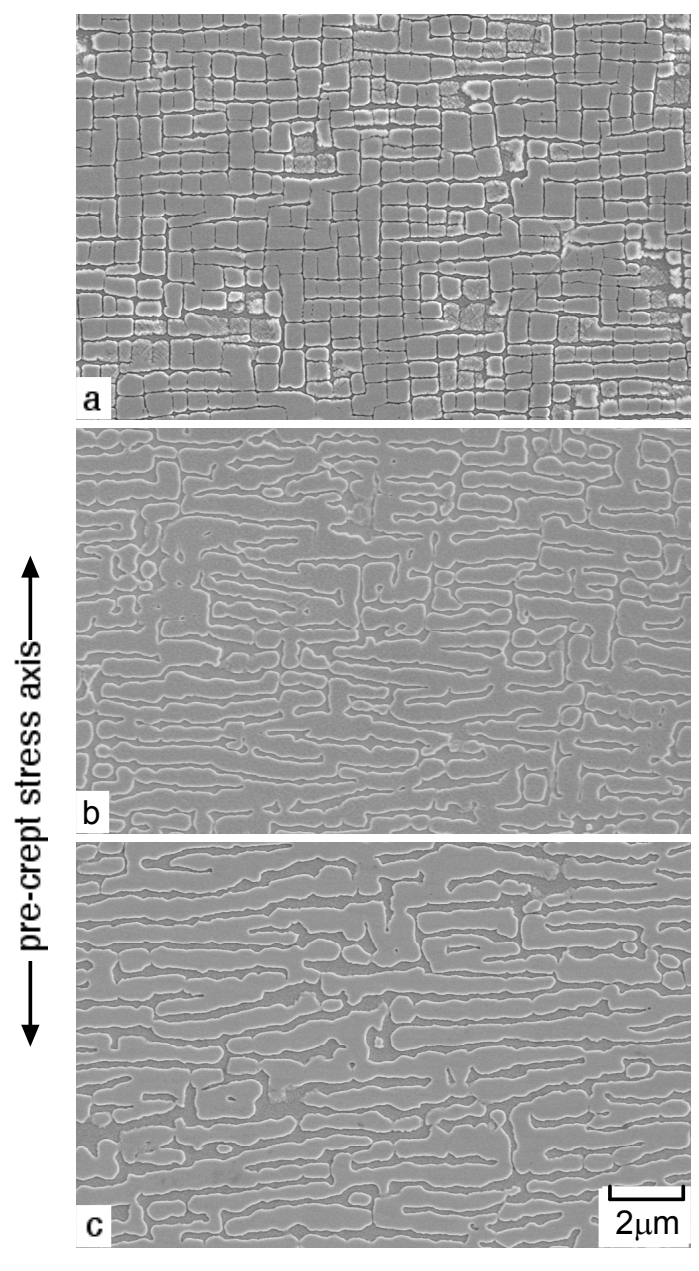

Fig. 3. The scanning electron micrographs of (a) the interrupted creep specimen at the strain of 0.01 and the specimens aged for (b) $1.08 \times 10^{6}$ and (c) $3.60 \times 10^{6} \mathrm{~s}$.

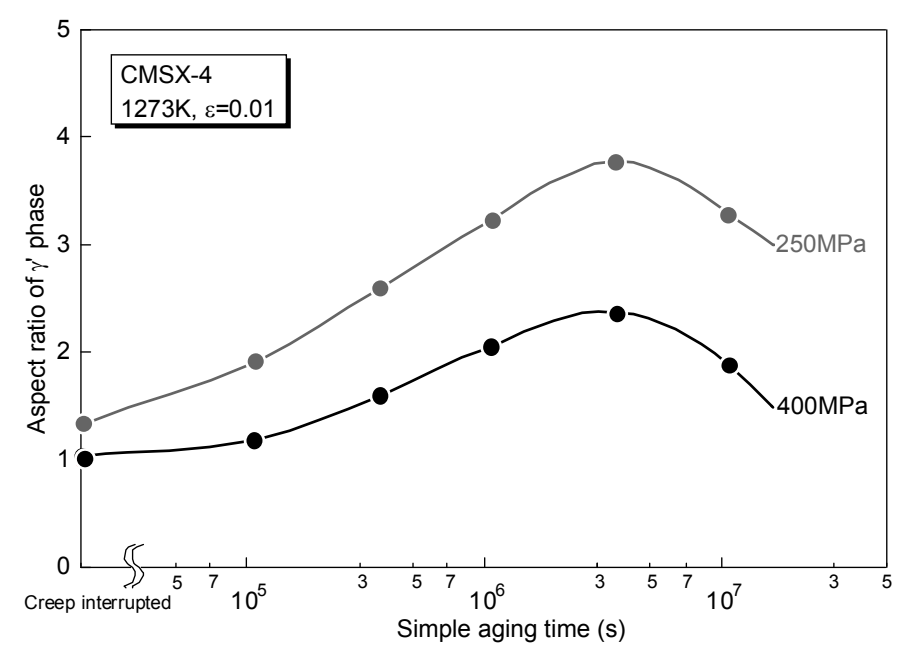

Fig. 4. Changes in the aspect ratio of the $\gamma^{\prime}$ precipitates of the interrupted creep specimens at 400 and $250 \mathrm{MPa}$ with simple aging time. 
where the incident beam direction, $\mathrm{B}$, is closed to [001]. There are a lot of dislocations which are tangled with each other at the $\gamma / \gamma^{\prime}$ interfaces.

The transmission electron micrograph of the specimen aged for 3.60x $10^{6} \mathrm{~s}$ is shown in Fig. 6, where $\mathrm{B}=[001]$. Though a large number of dislocations locate at the $\gamma / \gamma^{\prime}$ interfaces, these dislocations are rearranged regularly and partially lead to the formation of the dislocation networks. In this way, the number of dislocations at the $\gamma / \gamma^{\prime}$ interfaces seems to be constant independent of aging time, and these dislocations are rearranged regularly with increasing simple aging time.

\section{Dislocation density at the $\gamma / \gamma^{\prime}$ interfaces}

The dislocation density at the $\gamma / \gamma^{\prime}$ interfaces is regarded as the quantitative parameter showing the change in the dislocation substructures at the $\gamma / \gamma^{\prime}$ interfaces with simple aging time. In order to make the quantitative measurement of the dislocation density, it must be understood that there are two invisibility conditions on the basis of the $g \cdot b=0$ invisibility criterion. For example, when the TEM observations are performed with the incident beam directions, $\mathrm{B}=[001]$, and the g-vector, $g=[020]$, dislocations with Burgers vectors of [101] and [10-1] are invisible, and when the TEM observations are performed with $\mathrm{B}=[001], \mathrm{g}=[200]$, the dislocation cannot be observed by using only one $g$-vector and then the accurate dislocation density cannot be estimated. The TEM observations should be carried out with two different g-vectors on the same region and the image with one g-vector should be superimposed on the other to express the accurate dislocation substructures at the $\gamma / \gamma^{\prime}$ interfaces.

The TEM observations where $\mathrm{B}=[001], \mathrm{g}=[020]$ and [200], are performed in the same region at the $\gamma / \gamma^{\prime}$ interfaces, by using the specimen aged for $3.60 \times 10^{6} \mathrm{~s}$, and these two images are superimposed, as shown in Fig.7. The accurate expression of all dislocations at the $\gamma / \gamma^{\prime}$ interfaces can be attained by the TEM observations with the two different g-vectors on the same area.

The change in the dislocation density at the $\gamma / \gamma^{\prime}$ interfaces with simple aging time are shown in

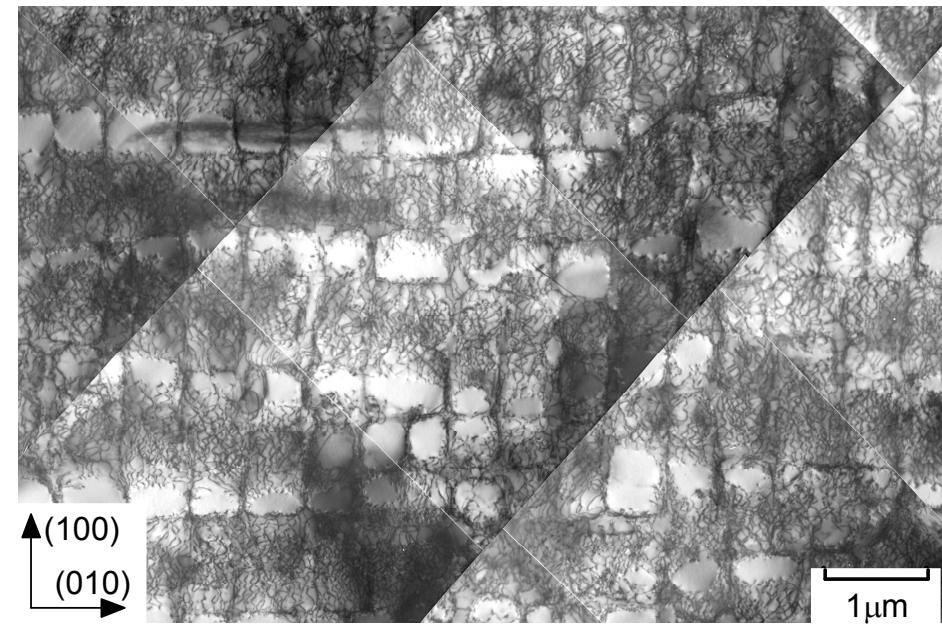

Fig. 5. The transmission electron micrograph of the interrupted creep specimen at the strain of $0.01, \mathrm{~B}=[001]$.

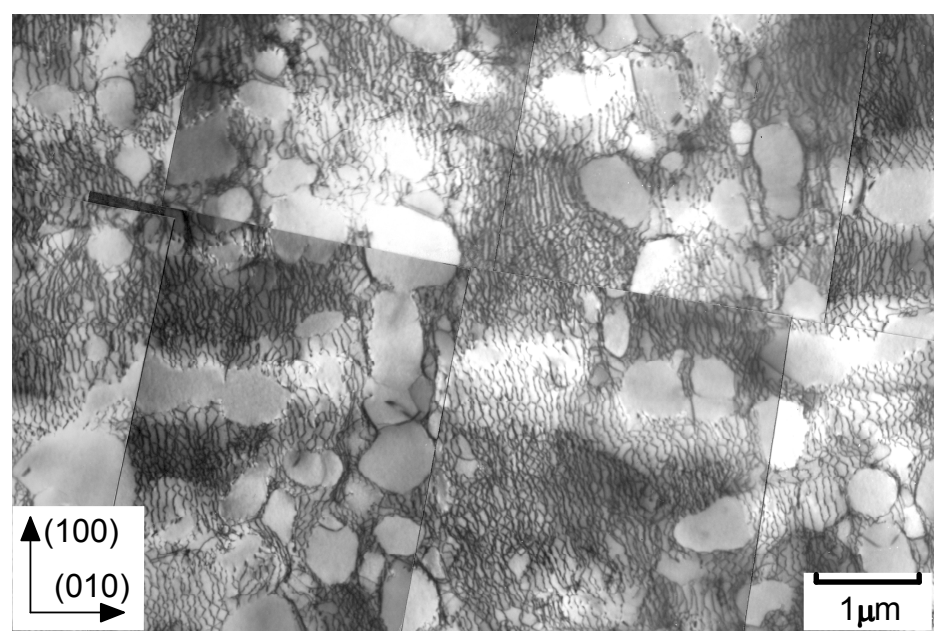

Fig. 6. The transmission electron micrograph of the interrupted creep specimen aged for $3.60 \times 10^{6} \mathrm{~s}$, where $\mathrm{B}=[001]$.

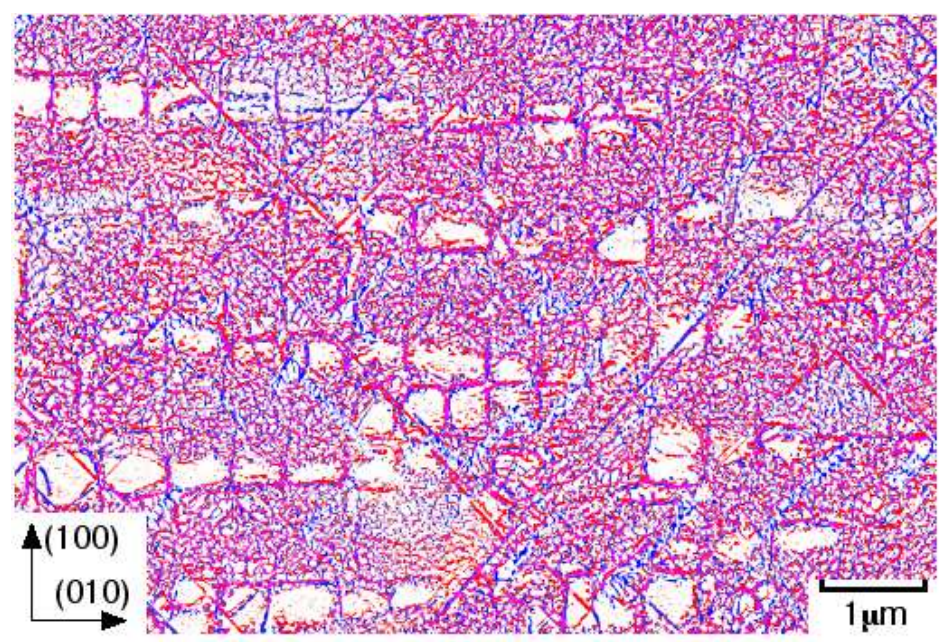

Fig. 7. Superimposed image of transmission electron micrographs where $\mathrm{B}=[001], \mathrm{g}=[020]$ and [200], on the same region at the $\gamma / \gamma^{\prime}$ interfaces, by using the specimen aged for $3.60 \times 10^{6} \mathrm{~s} .(\mathrm{g}=[020]$ : red, [200]: blue, $[020]+[200]$ : purple) 
Fig.8, compared with that of the interrupted creep specimen at $250 \mathrm{MPa}$. There is no difference between the dislocation density at the $\gamma / \gamma^{\prime}$ interfaces of the interrupted creep specimens at 400 and $250 \mathrm{MPa}$ and the dislocation density at the $\gamma / \gamma$ ' interfaces doesn't change with increasing aging time at both stresses. These dislocation densities are about 4 orders of magnitude higher than those which are estimated from the misfit dislocation (when line vector of misfit dislocation $=<100>$, lattice parameter of $\gamma$ phase, $\mathrm{a}=0.3589 \mathrm{~nm}$ and misfit of $\gamma / \gamma^{\prime}$ phase, $\delta=$ $-6.782 \times 10^{-4}, \rho_{\text {misfit dislocation }}=10^{9} \mathrm{~m}^{-2}$ ). From these results, the dislocation at the $\gamma / \gamma^{\prime}$ interfaces does not seem to be the misfit dislocation.

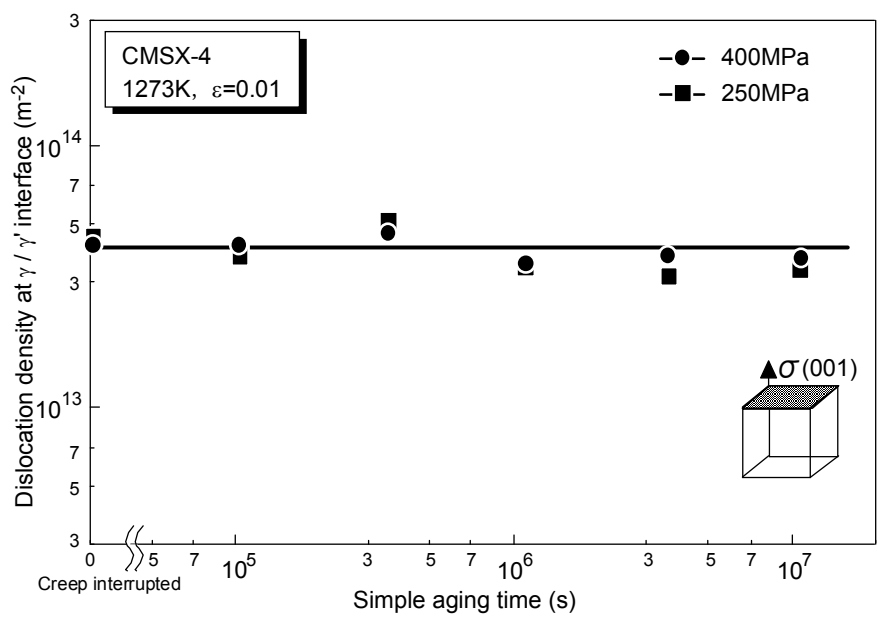

Fig. 8. The change in the dislocation density at the $\gamma / \gamma^{\prime}$ interfaces with simple aging time.

\section{Burgers vectors of dislocations at $\gamma / \gamma^{\prime}$ interfaces}

The Burgers vectors of dislocations at the $\gamma / \gamma^{\prime}$ interfaces are identified in this section. In general, mobile dislocations of FCC metals have six kinds of the $<110>$ Burgers vectors [13]. Four invisibility conditions where required for identifying a Burgers vector using the $g \cdot b=0$ invisibility criterion. The TEM observations on the same region are carried out with two incident beam directions, $\mathrm{B}=\{001\}$ and $\{101\}$ and four $\mathrm{g}$-vectors, $\mathrm{g}=<200>$ and $<-111>$.

The Burgers vectors of dislocations at the $\gamma / \gamma^{\prime}$ interfaces of the interrupted creep specimen at the strain of 0.01 are shown in Fig.9. All dislocations at the $\gamma / \gamma^{\prime}$ interfaces with six kinds of the $<110>$ Burgers vectors are observed. The Burgers vectors of all dislocations at the $\gamma / \gamma$ interfaces of the aged specimens are identified in same way (Fig.9). Based on this identification procedure, quantitative comparisons between the ratio of six kinds of the $<110>$ Burgers vectors to all dislocations and aging time are examined.

The ratios of dislocations at the $\gamma / \gamma^{\prime}$ interfaces with six kinds of the $<110>$ Burgers vectors to all dislocations of the interrupted creep specimens at 400 and $250 \mathrm{MPa}$, and then aged for $1.08 \times 10^{6}$ and $3.60 \times 10^{6} \mathrm{~s}$ are shown in Fig.10. At 400 and $250 \mathrm{MPa}$, all dislocations at the $\gamma / \gamma^{\prime}$ interfaces are identified as six kinds of the $<110>$ Burgers vectors and the ratio of dislocations at the $\gamma / \gamma^{\prime}$ interfaces with six kinds of the $<110>$ Burgers vectors to all dislocations is nearly equal irrespective of aging time. Consequently, it is suggested that dislocations at the $\gamma / \gamma^{\prime}$ interfaces are regarded as not the misfit dislocations, but the traces of mobile dislocations in the $\gamma$ channels which led to creep deformation, because of no change in the dislocation density with aging, high dislocation density and dislocations with six kinds of the $<110>$ Burgers vectors. And the formation of the rafted $\gamma / \gamma^{\prime}$ structures might be correlated with the rearrangement of tangled dislocations at the $\gamma / \gamma^{\prime}$ interfaces.

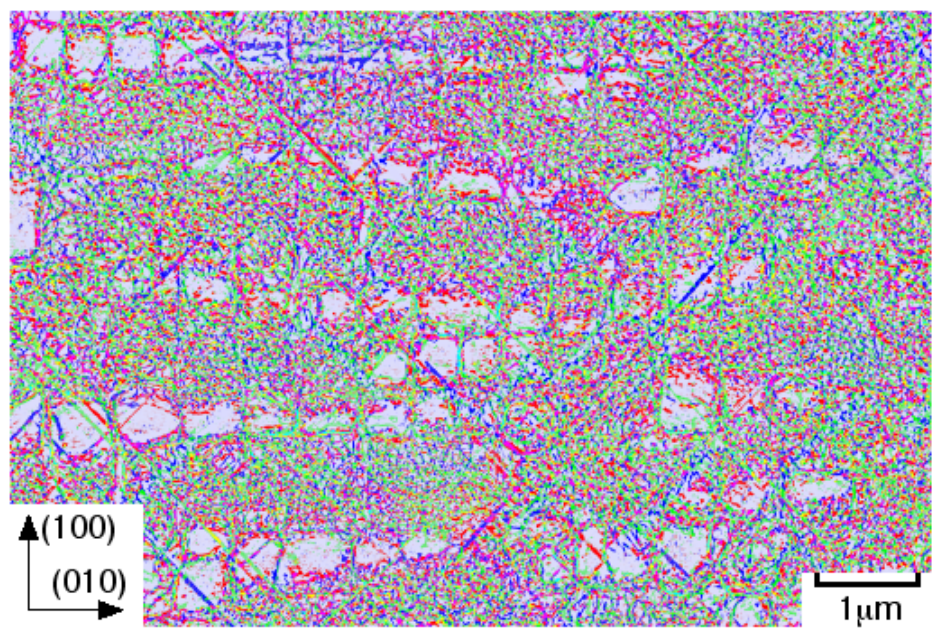

Fig. 9. The Burgers vectors of dislocations at the $\gamma / \gamma^{\prime}$ interfaces of the interrupted creep specimen at the strain of 0.01 . $(b=[110]$ : sky-blue, [1-10] : green, [10-1] : purple, [101] : blue, [011] : red, [01-1] : yellow) 


\section{Summary}

Simple aging at $1273 \mathrm{~K}$ is carried out on the single crystal nickel-based superalloy, CMSX-4, interrupted at the strain of 0.01 at $1273 \mathrm{~K}$ and $400 \mathrm{MPa}$, and the change in the dislocation substructures at the $\gamma / \gamma^{\prime}$ interfaces with increasing simple aging time is discussed. The following conclusions are obtained.

1) The $\gamma^{\prime}$ precipitates of the interrupted creep specimen at the strain of 0.01 at $1273 \mathrm{~K}$ and 400MPa, are still cuboidal. However, the cuboidal $\gamma^{\prime}$ precipitates changed to the rafted $\gamma / \gamma$ ' structures perpendicular to the pre-creep stress axis by aging.

2) The aspect ratio of the $\gamma^{\prime}$ precipitates of the interrupted creep specimen increases with increasing aging time, and attained to the maximum value.

3) There are a lot of dislocations which are tangled with each other at the $\gamma / \gamma^{\prime}$ interfaces of the interrupted creep specimen. These tangled dislocations are rearranged regularly with increasing aging time.

4) The dislocation density at the $\gamma / \gamma^{\prime}$ interfaces doesn't change with increasing aging time.

5) The ratio of dislocations at the $\gamma / \gamma^{\prime}$ interfaces with

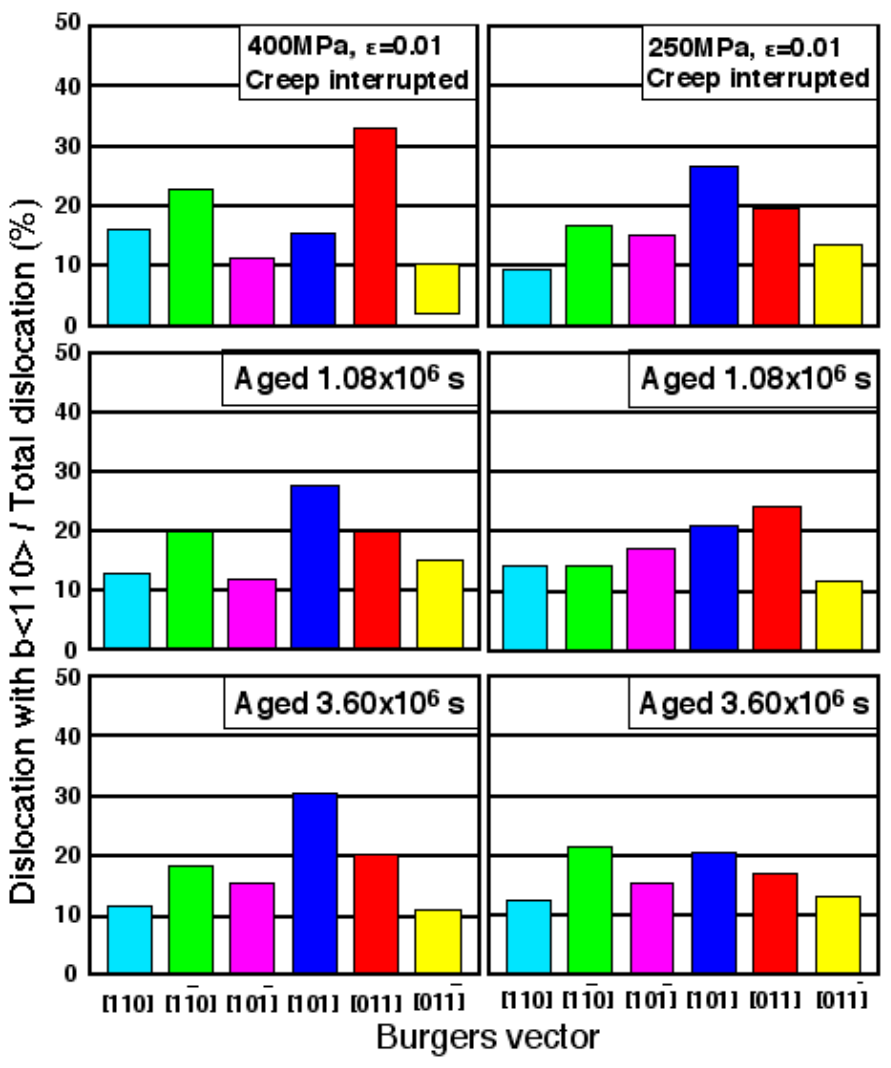

Fig. 10. The ratios of dislocations at the $\gamma / \gamma^{\prime}$ interfaces with six kinds of the $<110>$ Burgers vectors to all dislocations of the interrupted creep specimens at 400 and $250 \mathrm{MPa}$, and then aged for $1.08 \times 10^{6}$ and $3.60 \times 10^{6} \mathrm{~s}$. six kinds of the $<110>$ Burgers vectors to all dislocations is nearly equal, independent of aging time.

6) From these results, it is concluded that dislocations at the $\gamma / \gamma^{\prime}$ interfaces are regarded as not the misfit ones, but the traces of mobile dislocations in the $\gamma$ channels. Consequently, the formation of the rafted $\gamma / \gamma^{\prime}$ structures might be correlated with the rearrangement of tangled dislocations at the $\gamma / \gamma^{\prime}$ interfaces.

\section{References}

1)A. Pineau : Acta Metall., 24(1976), p.559.

2) F. R. N. Nabarro : Metall. Mater. Trans., 27A(1996), p.513.

3) M. Fahrmann, E. Fahrmann, O. Paris, P. Fratzland T. M. Pollock : Proc. 8th Int. Symp. on Superalloys 1996, (1996), p.191

4) J. K. Tien and R. P. Ganble : Metall. Trans, 3A(1972), p.2157.

5) D. Mukhherji, H. Gabrisch, W. Chen, H. J. Fecht and R. P. Wahi : Acta Mater., 44 (1997), p.3143.

6) T. M. Pollock and A. S. Argon : Acta Metall. Mater., 40(1992), p.1.

7) S. D. Eshelby : Proc. R. Soc. A, 2471(1957), p.376.

8) T. P. Gabb, S. L. Draper, D. R. Hull, R. A. MacKay and V. Nathal : Mater. Sci. Eng. A118(1989), p.59.

9) T. Ohashi, K. Hidaka and S. Imano : Acta Mater., 45(1997)5, p.1801.

10) N. Matan, D. C. Cox, C. F. M. Rae and R. C. Reed: Acta Mater., 47(1999)7, p.2031.

11) N. Miura, Y. Kondo and T. Matsuo : Proc. 9th Int. Conf. on Creep and Fracture Engineering Materials and Structures, ed. by J. D. Parker, Institute of Materials, London, (2001), 437.

12) N. Miura, K. Kurita, Y. Kondo and T. Matsuo : Mater. Sci. Forum, 539-543(2007), 3024.

13) K. Kurita, N. Miura, Y. Hayashi and Y. Kondo : $123^{\text {rd }}$ Committee on Heat Resisting Metals and Alloys Rep., 47(2006), p.345.

14) M. Kato : Introduction to the Theory of Dislocations, Shokabo, Tokyo, (1999), p.78. 